\title{
Unsteady Double Diffusive Natural Convection with Dufour and Soret Effects
}

\author{
Hamza Ben Niche, Said Bouabdallah, Badia Ghernaout and Mohamed Teggar* \\ Laboratory of mechanics, University Amar Telidji, Laghouat 03000, Algeria \\ Email: m.teggar@lagh-univ.dz
}

\begin{abstract}
Transient double diffusive natural convection in a square cavity is numerically investigated. The enclosure is heated and cooled along the vertical walls with thermal and solutal gradients, the two horizontal walls of the enclosure are adiabatic and impermeable, the Dufour and Soret effects are considered. The governing equations are solved by using control volume method and SIMPLER algorithm. The main focus of this work is to identify the flow regime for thermal and solutal dominated flows. The flow pattern and heat and mass transfer and the effect of various parameters are analyzed (thermal Rayleigh number, Buoyancy ratio, Soret and Dufour coefficients). Comprehensive Nusselt and Sherwood numbers data are presented as functions of the governing parameters. The results showed that both heat and mass transfer increased in the presence of Dufour coefficient, and the Soret coefficient had great effect on the flow structure.
\end{abstract}

Keywords: Double diffusive, Natural convection, Dufour, Soret, Oscillatory flow.

\section{INTRODUCTION}

The combination of temperature and concentration gradients in the fluid leads to buoyancy-driven flows. This fact has an important influence on the solidification process in a binary system [1]. When heat and mass transfer occur simultaneously, a complex fluid motion called doublediffusive convection takes place. Actually, double-diffusion occurs in a wide range of scientific fields such as oceanography, astrophysics, geology, biology and chemical processes [2]. Ostrach [3] and Viskanta et al. [4] reported complete reviews on the double-diffusion convection. Bejan [5] presented a fundamental study of scale analysis relative to heat and mass transfer within cavities; the cavities investigated were submitted to horizontal combined and pure temperature and concentration gradients.

If heat transfer is associated with mass transfer in a moving fluid, the relations between the fluxes and the driving potentials are of a more intricate nature. Energy flux can be generated not only by temperature gradients, but also by concentration gradients. The energy flux caused by a concentration gradient is known as Dufour effect. On the other hand, mass fluxes can also be created by temperature gradients and this is called Soret effect. In most of the studies related to heat and mass transfer process, Soret and Dufour effects are neglected on the basis that they are of a smaller order of magnitude than the effects described by Fourier's and Fick's laws, but these effects are considered as second order phenomena; but the effect of Duffor and Soret may become significant in areas such as hydrology, petrology, geosciences, etc. The Soret effect, for instance, has been utilized for isotope separation and in mixture between gases of both very light molecular weight and medium molecular weight [6].

During a double-diffusive convection process where the thermal and solutal buoyancies coexist, the Soret and Dufor effects play important roles on the flow and heat transfer phenomena. Recently, more studies on double-diffusive convection have been carried out taking into account the Soret and Dufor effects. Malashetty and Gaikwad [7] investigated the effect of Soret and Dufor effects on the double-diffusive convection, the authors analyzed a vertical unbounded stratified system combined with horizontal temperature and concentration gradients. Brand and Steinberg [8] studied numerically the convective instabilities of two miscible fluids in a porous medium with the Soret effect. Trevisan and Bejan [9] developed a double-diffusive convective model including both Soret and Dufour effects to predict heat transfer into a rectangular slot with uniform heat flux along the vertical sides. Nithyadevi and Yang [10] analyzed the effect of various parameters on double-diffusive convection of water in a partially heated enclosure with Soret and Dufour effects. A numerical analysis of the mixed convection flow with Soret effect in a two-sided lid-driven square cavity was performed by Bhuvaneswari et al. [11] using the SIMPLE algorithm. Joly et al. [12] studied the Soret effect on natural convection in a vertical enclosure; they analyzed the particular situation where the buoyancy forces induced equal intensities opposing thermal and solutal effects. Double diffusive and Soret effects, inducing convection in a shallow horizontal enclosure, was analytically and numerically studied by Bahloul et al. [13]. The same configuration was also investigated numerically by Mansour et al. [14]. The authors found that the Nusselt number 
decreased with increasing the Soret parameter while the Sherwood number increases or decreases with this parameter, depending on the temperature gradient induced by each solution.

As a comprehensive and typical flow problem, the doublediffusive convection is a strong and complex nonlinear coupled process; which was mainly controlled and influenced by parameters such as thermal Rayleigh number, buoyancy ratio, Prandtl number, Lewis number and aspect ratio. The buoyancy ratio is defined as the ratio of compositional buoyancy force to thermal buoyancy force [15]. Ghorayeb et al. [16] analyzed oscillatory convection flows in a square cavity under different Lewis numbers, the authors used the projection diffusion algorithm. Jiang et al. [17] studied unsteady double-diffusive transport phenomenon due to opposite buoyancy forces in shallow enclosures of various aspect ratios. The effects of buoyancy ratio on steady state and oscillatory of double-diffusive convection was studied by Nishimura et al. [18, 19].

This paper presents the results of a numerical study of steady-state and the onset of oscillatory double-diffusion in a square cavity; the cavity is filled with a binary mixture of undefined gas submitted to opposing temperature and concentration buoyancy forces. Firstly, the effects of thermal Rayleigh number, Dufour and Soret coefficients on fluid motion, heat and mass transfer rates are studied. Then, the combined effect of buoyancy ratio, Dufour and Soret coefficients are investigated.

\section{MATHEMATICAL FORMULATION}

The physical model considered in this study is schematically shown in Figure 1. An enclosure filled with a binary mixture of undefined gas. The temperatures $T_{h}$ and $T_{c}$ are uniformly imposed along the hot left and cold right walls, the top and bottom walls are assumed to be adiabatic and impermeable. The vertical walls are also submitted to opposing concentration buoyancy forces. It is assumed that all fluid properties are constant except density; which vary with temperature and concentration (Boussinesq's approximation), Newtonian viscous dissipation is assumed to be negligible. The effects of Dufour and Soret are considered.

$$
\rho=\rho_{0}\left[1-\beta_{T}\left(T-T_{0}\right)-\beta_{S}\left(C-C_{0}\right)\right]
$$

Dimensionless equations of the physical system: continuity, momentum, energy and species equations are:

$\frac{\partial U}{\partial X}+\frac{\partial V}{\partial Y}=0$

$\frac{\partial U}{\partial \tau}+U \frac{\partial U}{\partial X}+V \frac{\partial U}{\partial Y}=-\frac{\partial P}{\partial X}+\left(\frac{\partial^{2} U}{\partial X^{2}}+\frac{\partial^{2} U}{\partial Y^{2}}\right)$

$\frac{\partial V}{\partial \tau}+U \frac{\partial V}{\partial X}+V \frac{\partial V}{\partial Y}=$

$-\frac{\partial P}{\partial Y}+\left(\frac{\partial^{2} V}{\partial X^{2}}+\frac{\partial^{2} V}{\partial Y^{2}}\right)+\frac{R a}{\operatorname{Pr}}(\theta+N \Phi)$

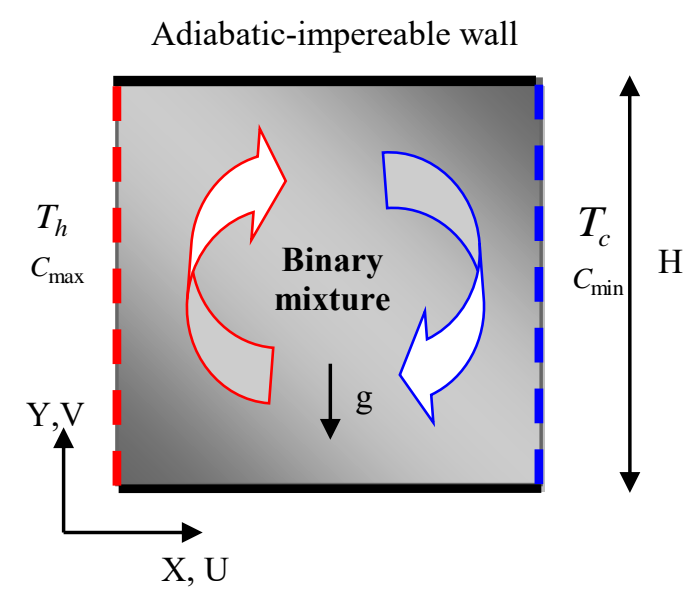

Figure 1. Physical problem and the monitoring points.

$$
\begin{aligned}
& \frac{\partial \theta}{\partial \tau}+U \frac{\partial \theta}{\partial X}+V \frac{\partial \theta}{\partial Y}= \\
& \frac{1}{\operatorname{Pr}}\left(\frac{\partial^{2} \theta}{\partial X^{2}}+\frac{\partial^{2} \theta}{\partial Y^{2}}\right)+D u\left(\frac{\partial^{2} \Phi}{\partial X^{2}}+\frac{\partial^{2} \Phi}{\partial Y^{2}}\right) \\
& \frac{\partial \Phi}{\partial \tau}+U \frac{\partial \Phi}{\partial X}+V \frac{\partial \Phi}{\partial Y}= \\
& \frac{1}{S c}\left(\frac{\partial^{2} \Phi}{\partial X^{2}}+\frac{\partial^{2} \Phi}{\partial Y^{2}}\right)+S r\left(\frac{\partial^{2} \theta}{\partial X^{2}}+\frac{\partial^{2} \theta}{\partial Y^{2}}\right)
\end{aligned}
$$

The dimensionless variables used are:

$$
\begin{aligned}
& X=\frac{x}{H} ; Y=\frac{y}{H} ; U=\frac{u}{v / H} ; \\
& V=\frac{v}{v / H} \tau=\frac{t}{H^{2} / v} ; \\
& P=\frac{p}{\rho_{0}(v / H)^{2}} ; \theta=\frac{T-T_{C}}{T_{h}-T_{C}} ; \Phi=\frac{C-C_{\min }}{C_{\max }-C_{\min }} ; \\
& N=\frac{\beta_{C}\left(C_{\max }-C_{\min }\right)}{\beta_{T}\left(T_{H}-T_{C}\right)} ; D u=\frac{K_{t c}\left(C-C_{\min }\right)}{\alpha\left(T_{H}-T_{C}\right)} ; \\
& S r=\frac{K_{c t}\left(T_{H}-T_{C}\right)}{D\left(C_{\max }-C_{\min }\right)}
\end{aligned}
$$

where $\mathrm{U}$ and $\mathrm{V}$ are the components of dimensionless velocity in the $\mathrm{X}$ and $\mathrm{Y}$ directions respectively. The thermal Rayleigh number is defined as:

$R a_{t}=\frac{g \beta_{t} \Delta T H^{3}}{v \alpha}$

where $\mathrm{g}$ is the gravitational acceleration, $\beta$ the fluid thermal expansion coefficient, $v$ is the fluid kinematical viscosity, $\mathrm{H}$ is the enclosure higth, and $\mathrm{Du}$ and $\mathrm{Sr}$ are the Dufour and Soret coefficients. 
Table 1. Comparison of our results with those of Wang et al. [15]

\begin{tabular}{lllll}
\hline & \multicolumn{2}{c}{ Jin Wang } & \multicolumn{2}{c}{ Present results } \\
\cline { 2 - 5 } & $N u$ & $S h$ & $N u$ & $S h$ \\
\hline$D u=S r=0.1$ & 5.88 & 6.92 & 5.80 & 6.92 \\
$D u=S r=0.2$ & 6.32 & 7.35 & 6.45 & 7.32 \\
$D u=S r=0.5$ & 7.62 & 8.55 & 7.98 & 8.36 \\
\hline
\end{tabular}

Table 2. Comparison of the present results and those of Nishimura [21] and Ghorayeb [22]

\begin{tabular}{llll}
\hline & $\begin{array}{l}\text { Present study } \\
\text { FV }\end{array}$ & FEM [21] & SM [22] \\
\hline$\tau_{0}$ & 0.049 & 0.0497 & 0.05091 \\
\hline $\operatorname{Max}\left|\Psi_{\max }\right|$ & 26.75 & 26.7 & 27.8 \\
$\operatorname{Min}\left|\Psi_{\max }\right|$ & 12.80 & 12.9 & 13.7 \\
$\operatorname{Max}\left|\Psi_{\min }\right|$ & 5.45 & 5.76 & 5.85 \\
$\operatorname{Min}\left|\Psi_{\text {min }}\right|$ & 0.40 & 0.351 & 0.333 \\
\hline
\end{tabular}

The initial and boundary conditions are as follows:

At $\tau=0$ :

$$
U=V=\theta=\Phi=0
$$

For $\tau>0$ :

$X=0 \quad U=V=\theta=\Phi=0$

$X=1 \quad U=V=0$ and $\theta=\Phi=1$

$Y=0 \quad U=V=\frac{\partial \theta}{\partial Y}=\frac{\partial \Phi}{\partial Y}=0$

$Y=1 \quad U=V=\frac{\partial \theta}{\partial Y}=\frac{\partial \Phi}{\partial Y}=0$

\section{NUMERICAL SOLUTION}

The governing equations (2-6) associated with the boundary conditions (7a-e) were solved numerically using the control-volume based method [20]. The central-difference scheme was used to discretize all the spatial terms. Fully implicit Euler method was used to update the solution in the time domain. A staggered grid system, in which the velocity components are stored midway between the scalar storage locations, was used. In order to couple the velocity field and pressure in the momentum equations, the SIMPLERAlgorithm was adopted. The solution of the fully coupled discretized equations was obtained iteratively using the TDMA method. In order to ensure that the results are grid size independent, different meshes were tested: $22 \times 22,42 \times$
42, $82 \times 82$ and $102 \times 102$. The difference between predictions of using $22 \times 22$ and $42 \times 42$ grids was less than $1 \%$ in $N u, S h, \psi_{\max }$ and $\psi_{\min }$. The difference between results obtained using $42 \times 42$ and $82 \times 82$ was less than $0.5 \%$. Most calculations presented in this paper were performed using non-uniform grids (with a geometric progression coefficient of 1.03). The results are presented by using dimensionless time step of $\tau=10^{-4}$ for the stationary solution and $\tau=2 \times 10^{-5}$ for the unsteady solution. Convergence at a given time step was considred when the maximum relative change between two consecutive iterations levels was less than $10^{-4}$ and this for all flow parameters.

\section{RESULTS}

The numerical results are obtained for different values of thermal Rayleigh number, Buoyancy ratio, Soret and Dufour coefficients. The parameters considered are respectively in the ranges $10^{3}<\mathrm{Ra}_{\mathrm{t}}<10^{6},-2<\mathrm{N}<0.0,0<\mathrm{Sr}<2.0$, $0.0<\mathrm{Du}<2.0$. The results are presented in different forms (streamlines, isotherms, isoconcentration and mid-height velocity profiles) to present the fluid flow and the heat and mass transfer phenomena both in transient and steady states. The heat and mass transfer rates in the enclosure were measured in terms of the average Nusselt number and average Sherwood number.

\subsection{Validation of the code}

In order to verify the accuracy of the present numerical study, the computer code was validated by comparison with the numerical results due to Jin Wang [15], for $\mathrm{Ra}_{\mathrm{t}}=10^{5}, \mathrm{Pr}$ $=1.0, \mathrm{Sc}=2.0$, and $\mathrm{N}=2.0$ (Figure 2), where the average Nusselt and Sherwood numbers are presented in Table 1. A good agreement between the obtained and reported results was observed, the maximum relative error between this work and that of Jin Wang [15] is less than 2.5\%. Table 2 presents a comparison of the present finite volumes solution with finite elements method of Nishimura et al. [21] in a hand and the spectral method used by Morega et al.[22] in the other hand. For oscillatory behavior in $\psi_{\max }$ and $\psi_{\min }$, and as predicted by these authors, the oscillation period was found to be 0.049 .

\subsection{Effect of thermal Rayleigh number $\left(\mathrm{Ra}_{\mathrm{t}}\right)$}

In this section, numerical results for the streamline, temperature and concentration contours and velocities profiles at mid-section of the enclosure are reported for various values of $\mathrm{Ra}_{\mathrm{t}}$, Dufour and Soret coefficients. In addition, representative results for the average Nusselt number and the average Sherwood number at various conditions are presented and discussed.

Figure 3 shows the effect of $R a_{t}$ on the double-diffusive convection and heat and mass transfer rates. It can be seen that $\mathrm{Nu}$ and $\mathrm{Sh}$ are almost unchanged while Rat is less than $8 \times 10^{3}$ because the system presents conduction-dominated heat transfer. Through fluid flow investigations, it is found that $\mathrm{Ra}_{\mathrm{t}}=8 \times 10^{3}$ presented a static bifurcation point; which flow structure develops from conduction-dominated into convection-dominated heat transfer. $\mathrm{Nu}$ and $\mathrm{Sh}$ numbers increased with $\mathrm{Ra}_{\mathrm{t}}>8 \times 10^{3}$ due to lager thermal buoyancy for convection-dominated heat transfer. When $\mathrm{Ra}_{\mathrm{t}}$ increased, it was clear that the average Nusselt and Sherwood numbers also increeasd as mentioned in Figure 3. 
a)
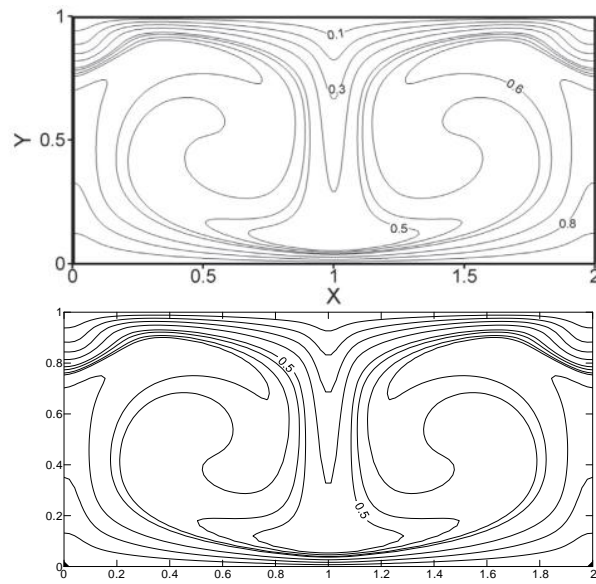

b)
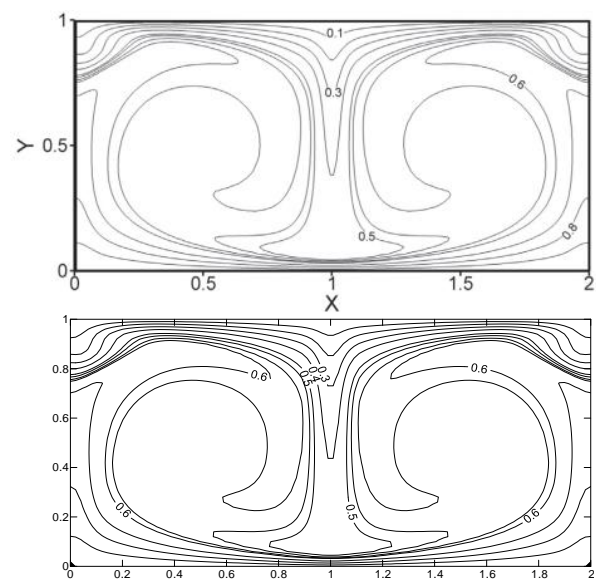

c)
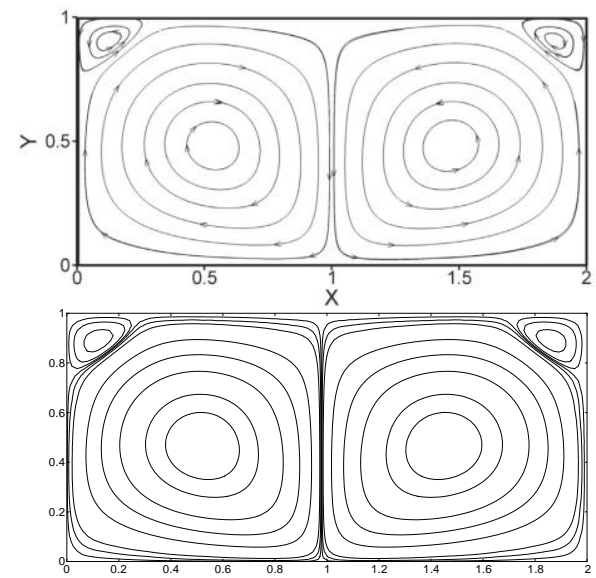

Figure 2. Comparison of our numerical results with thoses of Wang et al. [15] for differents coefficients a) $\mathrm{Du}=\mathrm{Sr}=0.1$,

b) $\mathrm{Du}=\mathrm{Sr}=0.2$ and c) $\mathrm{Du}=\mathrm{Sr}=0.5$

The effects of thermal Rayleigh number, thermal and solutal fields are illustrated in Figure 4. The following parameters are kept constant: $\mathrm{Sc}=2.0 ; \operatorname{Pr}=1.0$; and $\mathrm{N}=-$ 1.0. For low thermal Rayleigh number values $\mathrm{Ra}_{\mathrm{t}}<10^{3}$, the conduction regime was dominant in the cavity as shown Figure 4.a, indicating that most heat transfer was by conduction. Figure 4.a for $\mathrm{Ra}_{\mathrm{t}}=10^{4}$ presents a flow that consists of a very weak clockwise rotating cell with maximum strength $\psi_{\max }=3.29$. Furthermore, by increasing the thermal Rayleigh number to $\mathrm{Ra}_{\mathrm{t}}=5 \times 10^{4}$ and $\mathrm{Ra}_{\mathrm{t}}=10^{5}$, as shown in Figure 4.b and c, we observed streamlines intensification; which caused distortion in the central flowing cell. The maximum strength for the flowing cells in Figure 4.b was $\psi_{\max }=8.55$ for $\mathrm{Ra}_{\mathrm{t}}=5 \times 10^{4}$ and $\psi_{\max }=11.17$ for $\mathrm{Ra}_{\mathrm{t}}=10^{5}$.

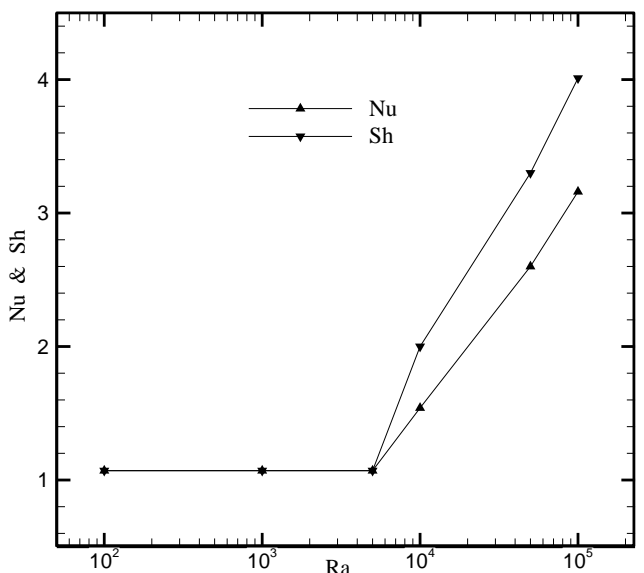

Figure 3. Variation of the average Nusselt and Sherwood numbers according to the thermal Rayleigh number

The fluid raises up on the hot wall and falls down the right cold wall; this leads to creation of thermal and solutal boundary layers at the upper part of the cold wall. Thermal and concentration gradients were very important in these regions. Consequently, we can note that the increase of thermal Rayleigh number had great effect on thermosolutal natural convection. It leads to intensify the fluid flow and to enhance the heat and mass transfer rates.

\subsection{Effect of Dufour coefficient}

Figure 5 shows the effect of Dufour coefficient on the mean Nusselt and Sherwood numbers for fixe value of Soret number $(\mathrm{Sr}=0.5)$. Both $\mathrm{Nu}$ and $\mathrm{Sh}$ increase with inceasing $\mathrm{Du}$ value. For $\mathrm{Du}<0.5$ the heat transfer rate was higher than mass transfer rate, and for $\mathrm{Du}>0.5$ the mass transfer rate became higher than the heat transfer rate. Wich may explain the solutal buoyancy force increase relatively to the thermal buoyancy force. The vertical velocity component in the middle of the cavity ( $\mathrm{Y}=0.5$ ) is depicted in Figure 6 for different Dufour values. It is shown that the flow incresed with increasing Dufour values, and the fluid particles moved with greater velocity for high value of $\mathrm{Du}\left(\mathrm{V}_{\max }=89.06\right.$ at $\mathrm{Du}$ $=2.0)$.

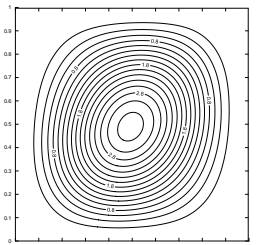

a) $\Psi_{\max }=3.29$

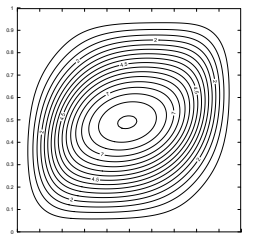

b) $\Psi_{\max }=8.55$

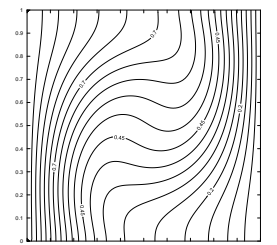

$S h=2.00$

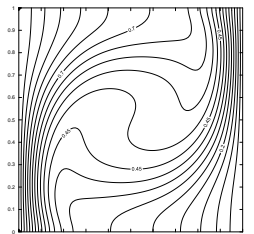

$S h=3.30$

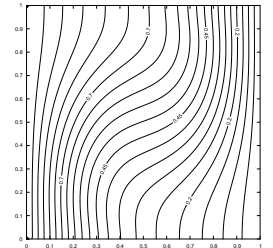

$N u=1.54$

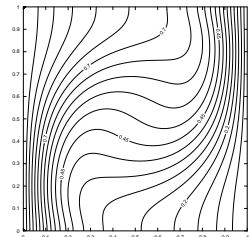

$N u=2.60$ 


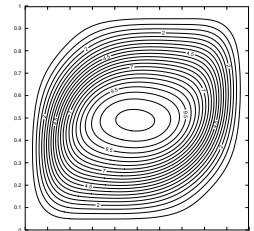

c) $\Psi_{\max }=11.17$

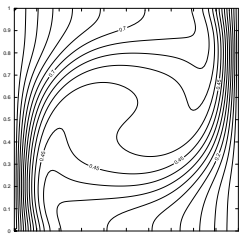

$S h=4.01$
$N u=3.16$

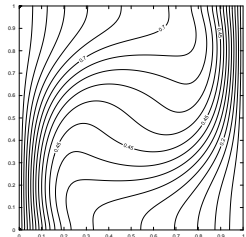

Figure 4. Steady state of streamlines (left), isotherms (middle) and isoconcentrations (right), for different thermal Rayleigh numbers a) $\mathrm{Ra}_{\mathrm{t}}=10^{4}$, b) $\mathrm{Ra}_{\mathrm{t}}=5 \times 10^{4}$ and c) $\mathrm{Ra}_{\mathrm{t}}=10^{5}$

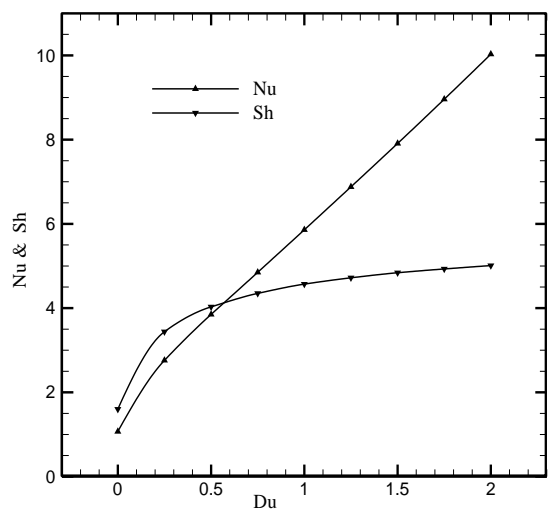

Figure 5. Effect of Dufour coefficient on the average Nusselt and Sherwood numbers

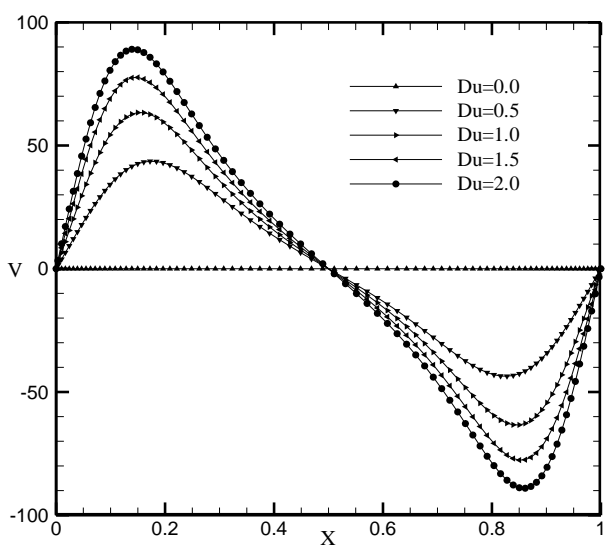

Figure 6. Profile of vertical velocity component in the middle of the cavity (at $Y=0.5$ ), for different Dufour coefficients $D u$

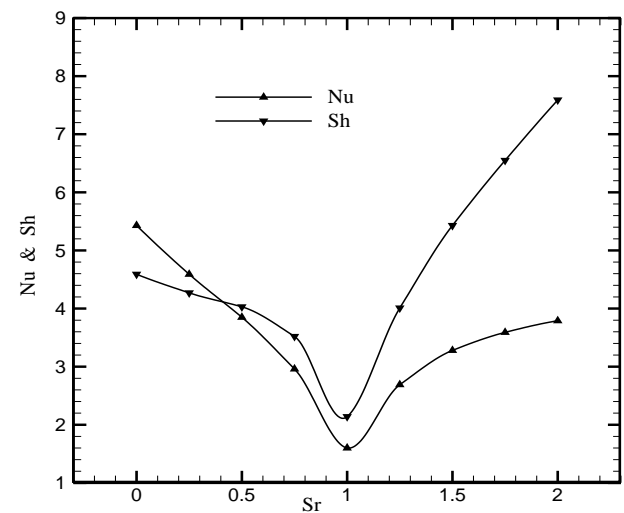

Figure 7. Effect of Soret coefficient on the average Nusselt and Sherwood numbers

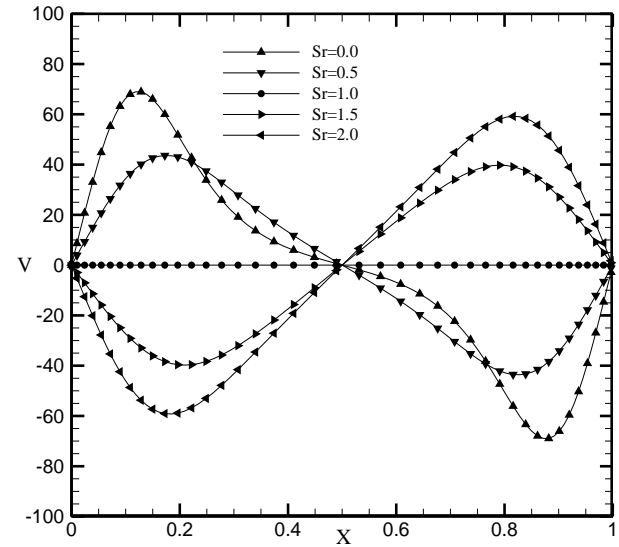

Figure 8. Vertical velocities respectively at $Y=0.5$, for different Soret coefficients $\mathrm{Sr}$

\subsection{Effect of Soret coefficient (Sr)}

Figure 7 shows the effect of Soret coefficient on the average Nusselt and Sherwood numbers. The results show that there was a critical value of $\mathrm{Sr}_{\mathrm{rc}}$ where the values of average $\mathrm{Nu}$ and $\mathrm{Sh}$ numbers were minimums. Both of the average Nusselt and average Sherwood numbers are decreasing with increasing values of $\mathrm{N}$ for $\mathrm{Sr}<\mathrm{Sr}_{\mathrm{cr}}$ and they increased with increasing values of $\mathrm{N}$ for $\mathrm{Sr}>\mathrm{Sr}_{\mathrm{cr}}$. It was also observed that for $\mathrm{Sr}<0.5$, the heat transfer rate was higher than the mass transfer rate, but for $\mathrm{Sr}>0.5$, the mass transfer rate was higher than the heat transfer rate. Figure 8 shows the mid-height vertical velocity profiles inside the cavity for different $\mathrm{Sr}$ values. It was observed that the fluid particle moved with greater velocity in the absence of Soret coefficient $\mathrm{Sr}$, and for $\mathrm{Sr}=1.0$, the velocity tended to zero $V_{\max }=0.5$, It was also noticed a reflection of velocities (negative values of velocities) for values of $\mathrm{Sr}>1.0$ because the flow changed its rotation direction. Consequently, the presence of Soret coefficient had grad effect on both heat and mass transfer rates and fluid velocity.

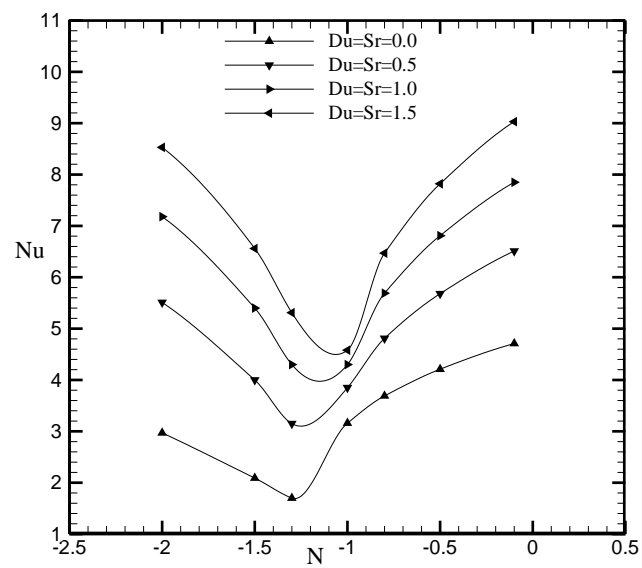

a) 


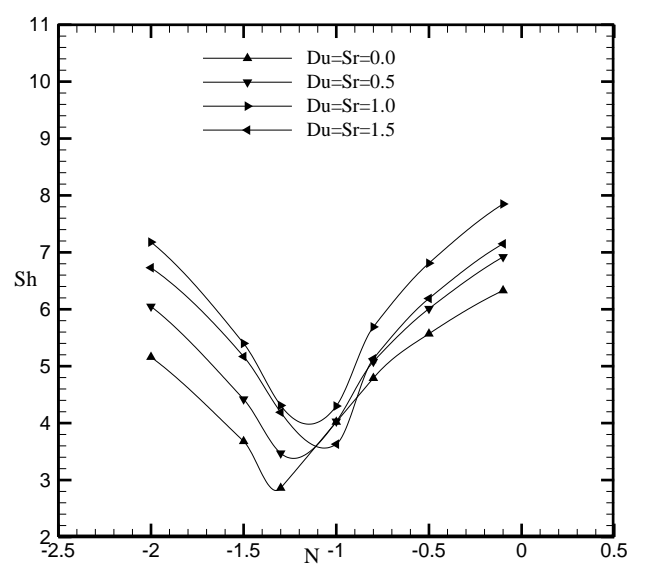

b)

Figure 9. Effect of buoyancy ratio $N$ on the: (a) Nusselt numbers; (b) Sherwood numbers

\subsection{Combined effect}

Figure 9 shows the effect of buoyancy ratio on the average Nusselt and Sherwood numbers. The results showed that there was a critical buoyancy ratio $\mathrm{N}_{\mathrm{cr}}$ where the values of average $\mathrm{Nu}$ and $\mathrm{Sh}$ numbers were minimums. Both of the average Nusselt and Sherwood numbers decreased with increasing values of $\mathrm{N}$ for $\mathrm{N}<\mathrm{N}_{\mathrm{cr}}$, and they were increased with increasing values of $\mathrm{N}$ for $\mathrm{N}>\mathrm{N}_{\text {cr. }}$. These behaviors were associated with the thermal- dominated and compositional-dominated regimes. The influence of Du and $\mathrm{Sr}$ coefficients on $\mathrm{Nu}$ and $\mathrm{Sh}$ numbers showed that the heat and mass transfer rates were higher, when the $\mathrm{Du}$ and $\mathrm{Sr}$ had higher values $(\mathrm{Du}=\mathrm{Sr}=1.5)$. The minimum values of the average Nusselt and Sherwood numbers were the same $(\mathrm{N}=$ 0.8 ) for different values of $\mathrm{Du}$ and $\mathrm{Sr}$, but the minimum value for higher values of $\mathrm{Du}=\mathrm{Sr}=2.0$ was $\mathrm{N}=-1.0$.

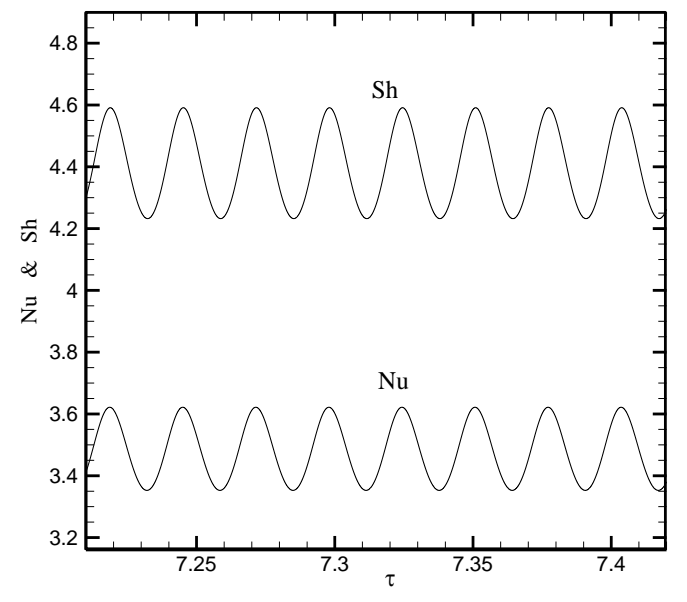

Figure 10. Time-dependent Nusselt and Sherwood numbers at monitoring points

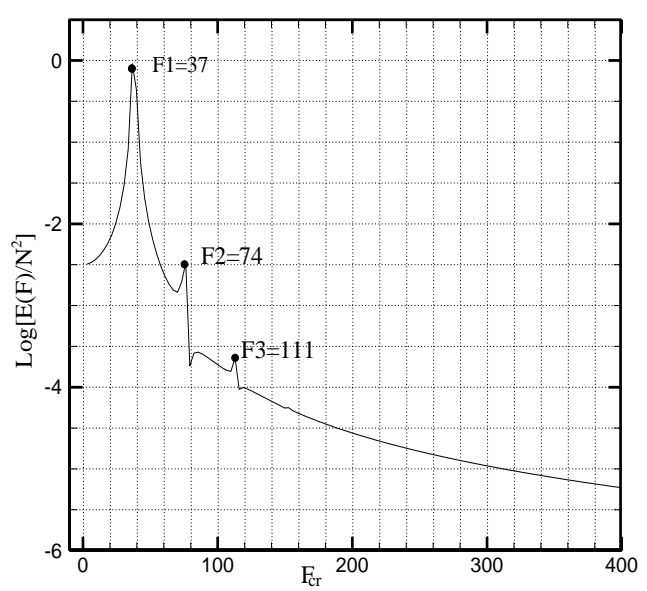

Figure 11. Power spectrum of the dimensionless horizontal velocity $U$

\subsection{Onset of oscillatory flow}

In order to illustrate the oscillations that result in oscillatory case for $\mathrm{N}=-1.0$ and Rat $=1.5 \times 10^{5}$, where steady state solution of $\mathrm{N}=-1.0$ and $\mathrm{Ra}_{\mathrm{t}}=10^{5}$ were used as initial values, periodic oscillatory flow appeared in a certain range of buoyancy ratio N. Figure 10 shows time profiles. In this problem, the steady solution is obtained for $\mathrm{Ra}_{\mathrm{t}}=10^{5}$.

The oscillatory unsteady solution appeared for $\mathrm{Ra}_{\mathrm{t}}=$ $1.5 \times 10^{5}$ as shown in figure 10 . This oscillatory behavior was discussed by Nishimura et al. [21] indicating that this oscillatory flow showed a periodic exchange between stable and unstable states in species stratification due to the interaction between thermal and compositional recirculations $(\mathrm{N}=-1)$. In the center of the enclosure, increasing or decreasing thermal recirculation lead to this exchange, while the compositional recirculation played an important role in the exchange at the upper and lower parts. To obtain the oscillations energy spectre, fast Fourier transformation (FFT) was used for certain number of values $\mathrm{Nb}=2^{15}$, corresponding to horizontal velocity. $F_{c r}$ denotes the energy peak which is the dominant frequency. This technique had been successfully used by Ghernaout et al. [23]. Figure 11 shows the variation of energy perturbations with their frequencies $\mathrm{n}_{3}$. For $\mathrm{F}_{\mathrm{cr}}=37$, which was the same in the other points, the dominant period was $1 / 37$.

\section{CONCLUSION}

In this study is examined the effects of Soret and Dufour numbers on an unsteady natural thermosolutal fluid flow. The flow characteristics for the velocity, temperature, concentration, Nusselt and Sherwood numbers are presented.

It is verified that for lower thermal Rayleigh number values, the conduction regime was dominant. Increasing the thermal Rayleigh number resulted in increasing intensities of the flow, heat and mass transfer rates in the enclosure.

- $\quad$ For fixed value of $\mathrm{Sr}=0.5$, increasing $\mathrm{Du}$ values resulted in increasing of the intensity within the cavity and increasing the heat and mass transfer inside the cavity.

- $\quad$ The fluid particle moved with greater velocity and high heat transfer rate for the high value of Dufour coefficient, the particle became slower with high mass transfer rate in the presence of Soret coefficient. 
- $\quad$ The critical value of the buoyancy ratio is equal to -0.8 for low values of $\mathrm{Du}$ and $\mathrm{Sr}$, and it was equal to -1.0 for $\mathrm{Du}=\mathrm{Sr}=2.0$. The values of the average Nusselt and Sherwood numbers increased with increasing the absolute values of buoyancy ratio.

- $\quad$ The transient unsteady flow appeared by the formation of regular (periodic) oscillations of particles in the flow when $\mathrm{Ra}_{\mathrm{t}}=1.5 \times 10^{5}$. The dominant period of oscillations calculated with FFT was 1/37.

\section{ACKNOWLEDGMENTS}

This paper was supported by the Research Team: Heat Transfer and Renewable Energy (HTRE) attached to the Mechanical Laboratory (LME), University of Laghouat (approved in 2009 under the number: 222 in 07/13/2009).

\section{REFERENCES}

[1] A. J. Chamkha and H. Al-Naser, "Hydromagnetic double-diffusive convection in a rectangular enclosure with opposing temperature and concentration gradients", Int. J. Heat and Mass Transfer, vol. 45, no. 12, pp. 2465-2483, 2002. DOI: 10.1016/S00179310(01)00344-1.

[2] C. Beghein, F. Haghighat and F. Allard, "Numerical study of double diffusive natural convection in a square cavity", Int. J. Heat Mass Transfer, vol. 35, no. 4, pp. 833-846, 1992. DOI: $\underline{10.1016 / 0017-}$ 9310(92)90251-M.

[3] S. Ostrach, "Natural convection with combined driving forces", Physico. Chem. Hydrodyn, vol. 1, pp. 233247, 1980.

[4] S. Kakac, W. Aung, R. Viskanta, Natural Convection: Fundamentals and Applications, Washington D. C.: Hemisphere, 1985.

[5] A. Bejan, "Mass and heat transfer by natural convection in a vertical cavity", Int. J. Heat Fluid Flow, vol. 6, no. 3, pp. 149-159, 1985. DOI: 10.1016/0142-727X(85)90002-5.

[6] D. Srinivasacharya and G. Swamy Reddy, "Double diffusive natural convection in Power-Law fluid saturated porous medium with Soret and Dufour effects", J. Braz. Soc. of Mech. Sci. \& Eng., vol. 34, no. 4, pp. 525-530, 2012. DOI:10.1590/S167858782012000400014.

[7] M. S. Malashetty, S. N. Gaikwad, "Effect of cross diffusion on double diffusive convection in the presence of horizontal gradients", Int. J. Eng. Sci., vol. 40, no. 7, pp. 773-787, 2002. DOI: 10.1016/S00207225(01)00097-0.

[8] H. R. Brand, V. Steinberg, "Convective instabilities in binary mixtures in a porous medium", Physica A, vol. 119, no. 1, pp. 327-338, 1983.

[9] O. V. Trevisan, A. Bejan, "Combined heat and mass transfer by natural convection in a vertical enclosure", Int. J. Heat Mass Transfer, vol. 109, no. 1, pp. 104112, 1987. DOI: $10.1115 / 1.3248027$.

[10] N. Nithyadevi, R. J. Yang, "Double diffusive natural convection in a partially heated enclosure with Soret and Dufour effects", Int. J. Heat Fluid Flow, vol. 30, no. 5, pp. 902-910, 2009. DOI: 10.1016/j.ijheatfluidflow.2009.04.001y
[11] M. Bhuvaneswari, S. Sivasankaran, Y. J. Kim, "Numerical study on double diffusive mixed convection with a Soret effect in a two-sided lid driven cavity", Numer. Heat Transfer A Appl., vol. 59, no. 7, pp. 543-560, 2011. DOI: 10.1080/10407782.2011.561077.

[12] F. Joly, P. Vasseur, G. Labrosse, "Soret-driven thermosolutal convection in a vertical enclosure", Int. Commun. Heat Mass Trans., vol. 27, no. 6, pp. 755764, 2000. DOI: 10.1016/S0735-1933(00)00156-1.

[13] A. Bahloul, N. Boutana, P. Vasseur, "Double-diffusive and Soret-induced convection in a shallow horizontal porous layer", J. Fluid Mech., vol. 491, pp. 325-352, 2003. DOI: $10.1017 / \mathrm{S} 0022112003005524$

[14] A. Mansour, A. Amahmid, M. Hasnaoui, M. Bourich, "Multiplicity of solutions induced by thermosolutal convection in a square porous cavity heated from below and submitted to horizontal concentration gradient in the presence of Soret effect", Num. Heat Trans., vol. 49, no. 1, pp. 69-94, 2006.

[15] Jin Wang, Mo Yang, Yuwen Zhang, "Onset of doublediffusive convection in horizontal cavity with Soret and Dufour effects", Int. J. Heat Mass Transfer, vol. 78, pp. 1023-1031, 2014. DOI: 10.1016/j.ijheatmasstransfer.2014.07.064.

[16] K. Ghorayeb, H. Khallouf, A. Mojtabi, "Onset of oscillatory flows in double diffusive convection", Int. J. Heat Mass Transfer, vol. 42, no. 4, pp. 629-643, 1999. DOI: $10.1016 / \mathrm{S} 0017-9310(98) 00204-X$.

[17] H. D. Jiang, S. Ostrach, Y. Kamotani, "Unsteady thermosolutal transport phenomena due to opposed buoyancy forces in shallow enclosures", J. Heat Transfer, vol. 113, no. 1, pp. 135-140, 1991. DOI: 10.1115/1.2910517.

[18] T. Nishimura, T. Imoto, M. Wakamatsu, "A numerical study of the structure of double-diffusive natural convection in a square cavity", in Proc. Symp. of $4^{\text {th }}$ ASME/JSME Thermal Engineering Conference, vol. 1, 1995, pp. 193-200.

[19] T. Nishimura, T. Imoto, M. Wakamatsu, "A numerical study of double-diffusive natural convection in a rectangular enclosure filled with binary gas", Trans. JSME Ser. B, vol. 62, no. 593, pp. 271-277, 1996. DOI: $10.1299 /$ kikaib.62.271.

[20] S. V. Patankar, "Numerical Heat Transfer and Fluid Flow", Washington, D.C.: Hemisphere, 1980.

[21] T. Nishimura, M. Wakamatsu, A.M. Morega, "Oscillatory double-diffusive convection in a rectangular enclosure with combined horizontal temperature and concentration gradients", Int. J. Heat Mass Transfer, vol. 41, no. 11, pp. 1601-1611, 1998. DOI: $\underline{10.1016 / \mathrm{S} 0017-9310(97) 00271-8 .}$.

[22] A. M. Morega, T. Nishimura, "Double diffusive convection by Chebyshev collocation method", Technol. Rep. Yamaguchi Univ., vol. 5, pp. 259-276, 1996.

[23] B. Ghernaout, S. Bouabdallah, M. Teggar and H. Ben niche, "Double Diffusive Natural Convection in Binary Mixture under the Effect of External Magnetic Field: Steady and Oscillatory State", Int. J. Heat and Technology, vol.33, no. 4, pp.11-18, 2015. DOI: 10.18280/ijht.330402. 


\section{NOMENCLATURE}

\section{Latin symbols}

$\mathrm{Ar} \quad$ aspect ratio

C dimensionless concentration

Du Dufour parameter

g gravitational acceleration $\left(\mathrm{m} . \mathrm{s}^{-2}\right)$

$\mathrm{H}$ enclosure height (m)

$\mathrm{N}$ buoyancy ratio

$\mathrm{Nu}$ average Nusselt number

Sh average Sherwood number

$\mathrm{Sr} \quad$ Soret parameter

$\mathrm{T}$ dimensionless temperature

$\mathrm{U}, \mathrm{V}$ dimensionless velocity components

W enclosure width (m)

$\mathrm{X}, \mathrm{Y}$ dimensionless coordinates

\section{Greek symbols}

$\alpha \quad$ thermal diffusivity $\left(\mathrm{m}^{2} \cdot \mathrm{s}^{-1}\right)$

$\theta \quad$ dimensionless temperature

$v \quad$ kinematic viscosity $\left(\mathrm{m}^{2} \cdot \mathrm{s}^{-1}\right)$

$\tau$ dimensionless time

$\psi \quad$ dimensionless stream function

$\phi \quad$ dimensionless concentration

\section{Subscripts}

c cold

cr critical

h hot wall

$\mathrm{T}$ thermal expansion

S Solutal expansion 